\title{
The benefits of emergency rescue and reanalysis data in decadal storm damage assessment studies
}

\author{
P. Jokinen, A. Vajda, and H. Gregow \\ Finnish Meteorological Institute, P.O. Box 503, 00101 Helsinki, Finland \\ Correspondence to: P. Jokinen (pauli.jokinen@fmi.fi)
}

Received: 23 January 2015 - Revised: 17 April 2015 - Accepted: 13 May 2015 - Published: 1 June 2015

\begin{abstract}
Studying changes in storm-induced forest damage in Finland has not been possible previously due to the lack of continuous, long series of impact data. We overcome this by combining emergency rescue data from the Finnish rescue services "PRONTO" (2011-) with ERA-Interim reanalysis data of wind gusts and soil temperatures to define exceedance thresholds for potential forest damage days. These thresholds were applied as a proxy for the period 1979-2013 in order to study the spatial and decadal characteristics of forest damage in Finland due to windstorms.

The results indicated that the area most impacted by potential forest damage was the south-western part of Finland along the coast, with 1-10 damaging storm cases per year. A decadal examination highlighted a lull period in the number of potential forest damage days during the 1990s compared to the 1980s and 2000s, albeit no trend was evident.

The inclusion of emergency rescue data allowed us for the first time to estimate the spatial distribution and decadal variations of potential forest damage days due to windstorms in Finland. The results achieved will encourage further development of thresholds for potential forest damage by including additional data sources and applying them to future climate scenarios.
\end{abstract}

\section{Introduction}

Extratropical storms can cause extensive socioeconomic impacts, by damaging infrastructure, disrupting society for several days or weeks, and even causing fatalities. Europe has experienced several high-impact storms in the past decade, such as "Kyrill" in 2007 (Levinson and Lawrimore, 2008), "Xynthia" in 2010 (Blunden et al., 2011) and "Dagmar" in 2011 (Blunden and Arndt, 2012). In fact, storms are the main natural hazard affecting Europe in terms of insured losses (Munich-Re, 2013).

Recent studies have indicated a decrease in the total number of extratropical cyclones, but an increase in the number of extreme cyclones over western and central Europe that enhance damage and economical losses (e.g. Donat et al., 2011; Zappa et al., 2013; Pinto et al., 2013). Thus, information about changes in storm impacts on infrastructure, society and economy in present and future climates is essential when planning adaptation and mitigation strategies for future adverse weather.
Storm-induced economic losses include damage to the forestry sector and infrastructure losses caused by fallen trees over power lines that then lead to power outages. In this study we will concentrate on the forest damage risks due to extratropical windstorms. Our study area is Finland, which is the most heavily forested country in Europe (FAO, 2010).

There are several factors that contribute to the risk of fallen trees, e.g. forest management, topography and tree type (Schmoeckel and Kottmeier, 2008). However, at higher latitudes, an important large scale factor in addition to strong winds is the soil conditions (Peltola et al., 1999). Limitations to root development, soil moisture and soil temperature, i.e. whether the ground is frozen or not, influence the vulnerability of forests to windthrows. Frozen soil anchors trees solidly to the ground and thereby makes them less liable to windthrow during storms relative to unfrozen soil conditions.

Our study aims to estimate recent changes in potential forest damage days by combining recent high quality forest damage observations with atmospheric and soil conditions 
from a reanalysis dataset. This will additionally demonstrate the benefits of including and combining new types of datasets within the larger context of improving and diversifying climate services.

\section{Data and methods}

ERA-Interim reanalysis data was used to create thresholds for wind gusts and soil temperatures on the days when forest damage occurred in Finland. These thresholds were then used as a proxy to utilise 35 years of ERA-Interim reanalysis data in order to obtain the decadal and spatial variation in potential forest damage days.

\subsection{Rescue data and fallen trees}

The statistics system of the Finnish rescue services, "PRONTO", stores information on various emergency rescue related incidents in Finland such as first response operations and building fires, that is when e.g. ambulances or the fire department are called to a location (Pronto, 2015). In addition, it includes cases related to natural disasters categorized according to different causes. Strong wind events were selected from this dataset, and it is estimated that at least $75 \%$ of these wind-related events were due to fallen trees that either fell over roads or downed power lines (A.-J. Punkka, personal communication, 10 December 2014). Thus, they were considered to be a good indicator of forest (tree) damage. The term "forest damage" is used although it is acknowledged that not all reported wind-related events were necessarily due to forest damage.

This dataset provided information on the place and time of forest damage caused by storms since the coordinates and times were included for each event reported to the emergency response centres. The rescue dataset starts in 2011, with data up until summer of 2014 used in this study. Since wind speeds related to small-scale summertime convective events are not captured by the coarse resolution reanalysis data, they were not included in our study. Therefore, only the months September to April were considered when defining the thresholds.

\subsection{Reanalysis data}

ERA-Interim reanalysis data (Dee et al., 2011) was used to define exceedance thresholds for wind gusts and soil temperatures on the days when forest damage occurred in Finland. ERA-Interim output covers the time period from 1979 onwards at a spatial resolution of $0.7^{\circ}$, which is approximately $80 \mathrm{~km}$ at the equator. Since the main contributors to possible forest damage conditions are wind speed and soil state (unfrozen conditions induce high risk), we utilise the ERAInterim $12 \mathrm{~h}$ forecasts of $10 \mathrm{~m}$ maximum wind gusts, and temporally-averaged soil temperature data provided at four levels: 0-7, 7-28, 28-100 and 100-255 cm.

\subsection{Combining the datasets}

The reanalysis maximum wind gust and average soil temperatures were extracted from two days prior to and including the day of the reported damage time in the "PRONTO" dataset by using the closest reanalysis grid point to the location of observed impact. Histograms of these variables were created that depicted the conditions leading to forest damage based on the overlapping time period of the two datasets (January 2011-April 2014). A combination of these thresholds was used as a proxy when selecting similar weather conditions in the ERA-Interim dataset from 1979 to 2013. The days when wind gusts at $10 \mathrm{~m}$ and soil temperatures at the four mentioned depths met or exceeded the defined thresholds were considered to be potential forest damage days.

\section{Results}

\subsection{Forest damage thresholds}

The histogram of ERA-Interim peak wind gusts corresponding to the days with observed wind damage is shown in Fig. 1. Although most damage reports given to the rescue services are logged almost immediately after the wind damage has occurred, there can sometimes be a much longer lag time between event and logging of the report, with no exact knowledge of when the damage occurred (e.g. people travelling to their summer cabins and finding damage that had occurred during the previous months). This is thought to explain some of the weaker wind speed values in the histogram. We therefore selected $19 \mathrm{~m} \mathrm{~s}^{-1}$ as the threshold for wind gusts as a clear jump in the number of damage events was observed above this value.

The histograms for the soil level temperatures at different levels depicted in Fig. 2 reveal that forest damage can occur even though the near surface layer temperature $(0-7 \mathrm{~cm})$ is slightly below freezing. However, on moving to deeper soil levels, the bulk of the histogram shifts to higher temperatures. These results suggest that trees can be uprooted when the near-surface level, down to a depth of $28 \mathrm{~cm}$, is frozen, but not when the deeper soil layers $(28-100 \mathrm{~cm})$ are frozen anchoring trees more securely to the ground; there were only few cases reported for frozen deep soil layers. This is in agreement with the earlier findings of Gregow (2013) suggesting that frozen soil conditions at a depth of $30 \mathrm{~cm}$ substantially reduced the risk of uprooting.

The combined threshold levels based on the wind gust and soil temperature histograms are summarized in Table 1. 
Table 1. The forest damage probability thresholds defined for the ERA-Interim dataset.

\begin{tabular}{ll}
\hline ERA-Interim parameter & Threshold \\
\hline Wind gusts & $\geq 19 \mathrm{~m} \mathrm{~s}^{-1}$ \\
$0-7 \mathrm{~cm}$ soil temperature & $\geq-2^{\circ} \mathrm{C}$ \\
$7-28 \mathrm{~cm}$ soil temperature & $\geq-1{ }^{\circ} \mathrm{C}$ \\
$28-100 \mathrm{~cm}$ soil temperature & $\geq 1{ }^{\circ} \mathrm{C}$ \\
$100-289 \mathrm{~cm}$ soil temperature & $\geq 3{ }^{\circ} \mathrm{C}$ \\
\hline
\end{tabular}

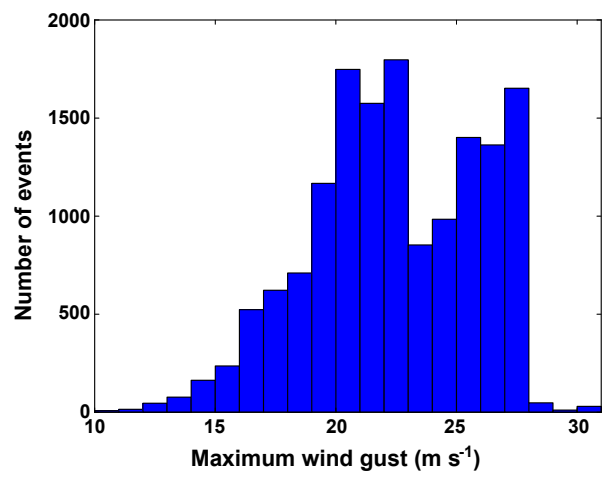

Figure 1. Histogram of the ERA-Interim maximum simulated wind gusts leading to observed forest damage.

\subsection{Potential forest damage days}

The average number of annual potential forest damage days in 1979-2013 is shown in Fig. 3. It indicates that the highest frequency is in the south-western parts of Finland along the coasts with values ranging between 1 and 10 per year. The lowest frequencies were found in the northern inland areas where forest damage conditions occurred on average less than once per year. This difference is most likely due to the longer duration of frozen ground in the north during the windy winter season and to the lower intensity of wind gusts in the more continental stable conditions. The spatial map in Fig. 3 also covers areas around Finland, although we must stress that the forest damage criteria was calibrated for Finland only and therefore values shown elsewhere are only suggestive; the thresholds would presumably require modification to accommodate different land surface and tree type.

Decadal maps in Fig. 3 as well as a time series of the areal average in southern and central parts of Finland (Fig. 4) indicate that the highest frequencies of potential forest damage conditions occurred in the mid-1980s and close to the year 2010 with a clear lull period during the 1990s. If the gust threshold only was considered, the number of damage days in the 1990s would have seen a peak. Thus the drop in the 1990s was due to lower soil temperatures on stormy days. There was also considerable variability from year to year, but no statistically significant trend existed for the time period covered in this study.
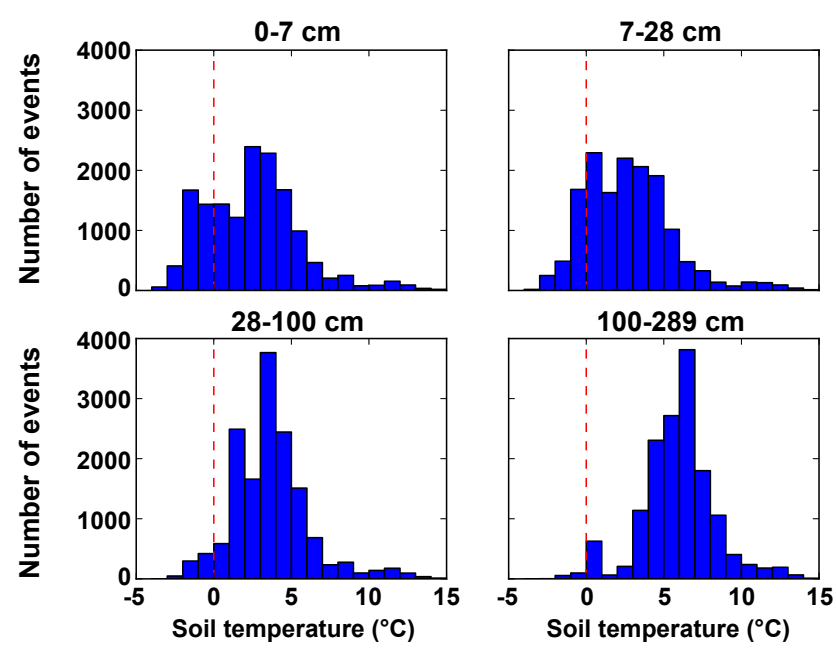

Figure 2. Histograms of ERA-Interim temperatures for four different soil levels leading to observed forest damage. The red dashed line highlights the $0^{\circ} \mathrm{C}$ temperature.

\section{Discussion and conclusions}

In this work, the benefits of combining emergency rescue data with reanalysis data were studied within the context of potential forest damage days in Finland. Although the calibration period for this study was relatively short, from 2011 to 2014, it did include six high-impact named storms in the study area (Tapani, 26 December 2011; Hannu, 27 December 2011; Antti, 30 November 2012; Eino, 17 November 2013; Oskari, 1 December 2013; Seija, 13 December 2013). Naturally, the thresholds will become more accurate as more data becomes available in the future. Furthermore, other weather factors such as wind direction and storm duration could be included in the list of parameters (Kupfer et al., 2008).

Future improvements in this method would include using the detailed impact data to calibrate the threshold values separately for each area (grid point) to account for the fact that forest type, and therefore damage conditions, vary from one location to another. For example, using Finnish thresholds would most likely not lead to similar damage in Germany. Additionally, the thresholds were specifically calibrated for ERA-Interim reanalysis data, which does not necessarily represent the thresholds that would be derived based on actual wind gust observations.

This study shows a large annual variation in the number of potential forest damage days in Finland, with the highest risk in the south-western parts of the country. The lowest number of damage-inducing storms was in the 1990s; this agrees well with the amount of forest damage compensation paid to forest owners due to wind damage, with higher amounts in the 1980s and 2000s compared to the 1990s (Ylitalo, 2010). This demonstrates that the inclusion of soil thresholds in the 

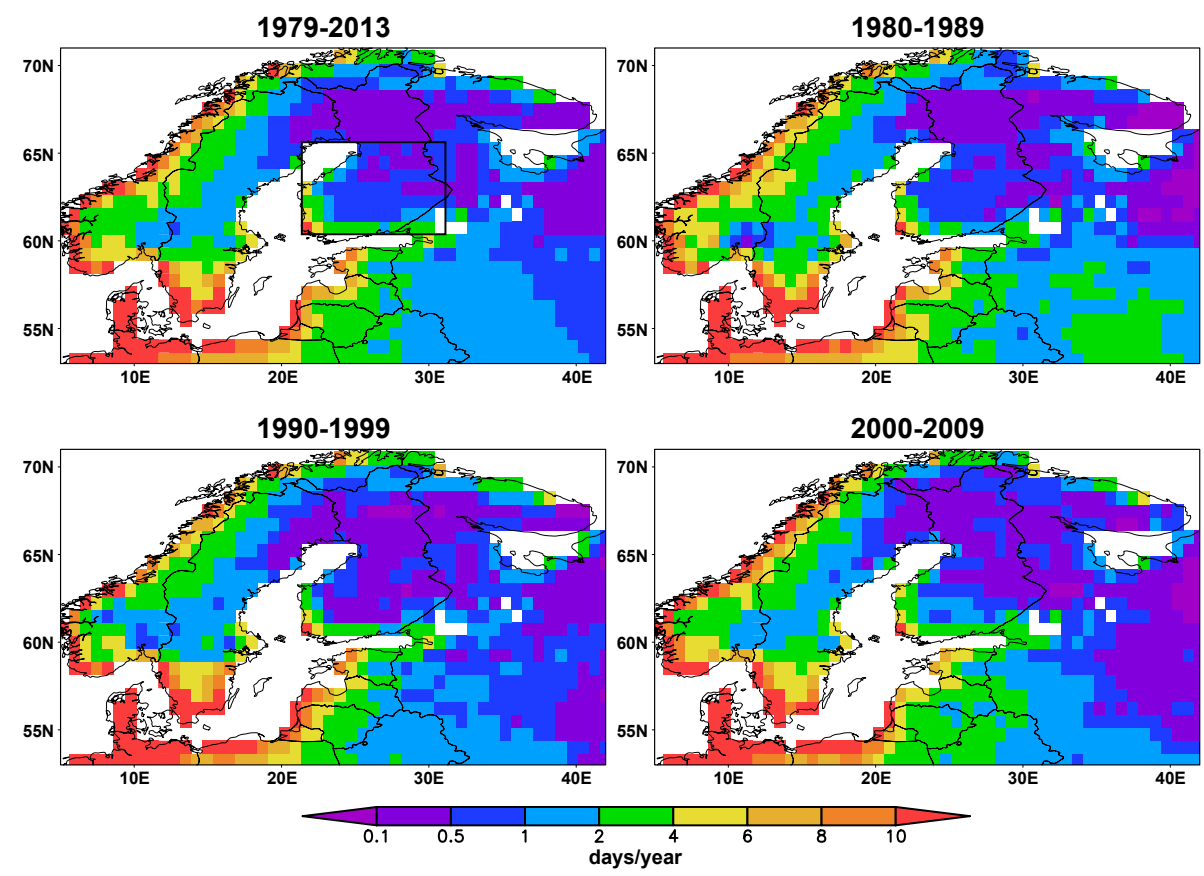

Figure 3. Potential forest damage days per year (days when the threshold levels are met or exceeded) in ERA-Interim during 1979-2013 (upper left panel) and decadal averages. The black box indicates the region over which the areal average in Fig. 4 is calculated.

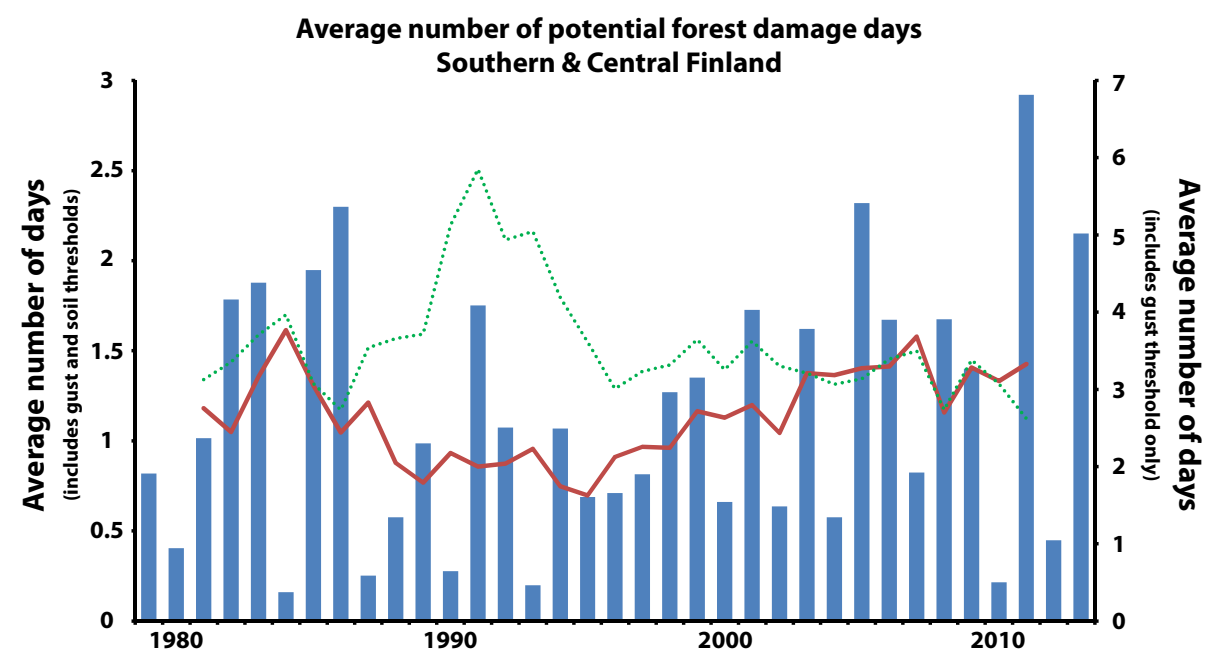

Figure 4. Blue columns are the average number of potential forest damage days in southern and central Finland based on ERA-Interim when wind gust and soil thresholds are met or exceeded. Vertical axis is on the left, and the red line is the 5-year running mean. The green dashed line is a 5-year running mean that uses the wind gust threshold only (vertical axis on the right). The values are calculated for the area depicted in Fig. 3.

assessment is a major improvement over using a wind-gust threshold only.

The most significant Finnish forest damage and rescue operations due to windstorms occurred during the Pyry-storm, 31 October 2001, and Janika-storm, 15 November 2001 (total forest damage $7.3 \mathrm{Mm}^{3}$ ). Additionally, the Tapani-storm (also called Dagmar) on 26 December 2011 caused $3.5 \mathrm{Mm}^{3}$ in forest damage (Gregow, 2013). Both these years were above average in our assessment of the number of potential forest damage days, although it should be noted that our methodology does not attempt to estimate the damage severity of individual storms.

This study has evaluated the feasibility of using emergency rescue data in conjunction with reanalysis data in storm damage studies. The collaboration in data sharing within the public sector has been fruitful and found to boost the effective- 
ness of weather and climate services in Finland. Since the aim of National Hydrological and Meteorological Services is also to serve the private sector, more cooperation in data sharing is required in this regard; for example, data from energy or telecommunication companies would be very valuable in storm-related impact research. As the data from private companies is rarely available, more effort is needed to collect valuable data from multiple sources, including the general public, in order to gain the most comprehensive view on past and future storm impacts.

Based on the present results we plan to develop the method further and apply it to future climate scenarios. With an accurate forest damage model we can then estimate how forest damage conditions in Finland are expected to change in the upcoming decades, providing useful information for adaptation and mitigation strategies.

Author contributions. Pauli Jokinen has prepared the manuscript and conducted the analyses. Andrea Vajda and Hilppa Gregow have supervised, commented and participated in writing.

Acknowledgements. This work was financially supported by the EU FP7 CORE-CLIMAX project. We are grateful to Ewan O'Connor for proofreading the manuscript. We also thank Carin Nilsson and one anonymous reviewer for their helpful comments.

Edited by: T. Cegnar

Reviewed by: two anonymous referees

\section{References}

Blunden, J. and Arndt, D.: State of the climate in 2011, B. Am. Meteorol. Soc., 93, S1-S282, doi:10.1175/2012BAMSStateoftheClimate.1, 2012.

Blunden, J., Arndt, D. S., and Baringer, M. O.: State of the climate in 2010, B. Am. Meteorol. Soc., 92, S1-S236, doi:10.1175/15200477-92.6.S1, 2011.

Dee, D. P., Uppala, S. M., Simmons, A. J., Berrisford, P., Poli, P., Kobayashi, S., Andrae, U., Balmaseda, M. A., Balsamo, G., Bauer, P., Bechtold, P., Beljaars, A. C. M., van de Berg, L., Bidlot, J., Bormann, N., Delsol, C., Dragani, R., Fuentes, M., Geer, A. J., Haimberger, L., Healy, S. B., Hersbach, H., Hólm, E. V., Isaksen, L., Kllberg, P., Köhler, M., Matricardi, M., McNally, A. P., Monge-Sanz, B. M., Morcrette, J.-J., Park, B.-K., Peubey, C., de Rosnay, P., Tavolato, C., Thépaut, J.-N., and Vitart, F.: The ERA-Interim reanalysis: Configuration and performance of the data assimilation system, Q. J. Roy. Meteorol. Soc., 137, 553597, doi:10.1002/qj.828, 2011.
Donat, M. G., Leckebusch, G. C., Wild, S., and Ulbrich, U.: Future changes in European winter storm losses and extreme wind speeds inferred from GCM and RCM multi-model simulations, Nat. Hazards Earth Syst. Sci., 11, 1351-1370, doi:10.5194/nhess-11-1351-2011, 2011.

FAO: Global Forest Resources Assessment 2010, Food and Agriculture Organization of the United Nations, Rome, Italy, available at: http://www.fao.org/forestry/fra/fra2010/en/ (last access: 10 January 2015), 2010.

Gregow, H.: Impacts of strong winds, heavy snow loads and soil frost conditions on the risks to forests in northern Europe, $\mathrm{Ph} . \mathrm{D}$. thesis, contributions 94, Finnish Meteorological Institute, Finland, 178 pp., 2013.

Kupfer, J., Myers, A., McLane, S., and Melton, G.: Patterns of Forest Damage in a Southern Mississippi Landscape Caused by Hurricane Katrina, Ecosystems, 11, 45-60, doi:10.1007/s10021-0079106-z, 2008.

Levinson, D. H. and Lawrimore, J. H.: State of the climate in 2007 , B. Am. Meteorol. Soc., 89, S1-S179, doi:10.1175/BAMS-89-7StateoftheClimate, 2008.

Munich-Re: Topics Geo Natural Catastrophes: Analyses, assessments, positions, Munich Re Publications, Munich, Germany, 64 pp., 2013.

Peltola, H., Kellomäki, S., and Väisänen, H.: Model computations of the impact of climatic change on the windthrow risk of trees, Climatic Change, 41, 17-36, 1999.

Pinto, J. G., Bellenbaum, N., Karremann, M. K., and DellaMarta, P. M.: Serial clustering of extratropical cyclones over the North Atlantic and Europe under recent and future climate conditions, J. Geophys. Res.-Atmos., 118, 12476-12485, doi:10.1002/2013JD020564, 2013.

Pronto: http://www.pelastusopisto.fi/fi/tutkimus-_jatietopalvelut/ tutkimus-_ja_kehittamispalvelut/tilastotpronto, last access: 10 January 2015.

Schmoeckel, J. and Kottmeier, C.: Storm damage in the Black Forest caused by the winter storm "Lothar" - Part 1: Airborne damage assessment, Nat. Hazards Earth Syst. Sci., 8, 795-803, doi:10.5194/nhess-8-795-2008, 2008.

Ylitalo, E. (Ed.): Finnish Statistical Yearbook of Forestry 2010, Finnish Forest Research Institute, Sastamala, Finland, 2010.

Zappa, G., Shaffrey, L. C., Hodges, K. I., Sansom, P. G., and Stephenson, D. B.: A multi-model assessment of future projections of north atlantic and european extratropical cyclones in the CMIP5 climate models, J. Climatol., 26, 5846-5862, 2013. 